\title{
Advancing the Understanding of the Role of Responsible Al in the Continued Use of IoMT in Healthcare
}

\author{
Fatema Al-Dhaen ${ }^{1} \cdot$ Jiachen Hou $^{1} \cdot$ Nripendra P. Rana ${ }^{2}$ (I) $\cdot$ Vishanth Weerakkody $^{3}$ \\ Accepted: 24 August 2021 \\ (C) The Author(s), under exclusive licence to Springer Science+Business Media, LLC, part of Springer Nature 2021
}

\begin{abstract}
This paper examines the continuous intention by healthcare professionals to use the Internet of Medical Things (IoMT) in combination with responsible artificial intelligence (AI). Using the theory of Diffusion of Innovation (DOI), a model was developed to determine the continuous intention to use IoMT taking into account the risks and complexity involved in using AI. Data was gathered from 276 healthcare professionals through a survey questionnaire across hospitals in Bahrain. Empirical outcomes reveal nine significant relationships amongst the constructs. The findings show that despite contradictions associated with AI, continuous intention to use behaviour can be predicted during the diffusion of IoMT. This study advances the understanding of the role of responsible AI in the continued use of IoMT in healthcare and extends DOI to address the diffusion of two innovations concurrently.
\end{abstract}

Keywords Internet of medical things $\cdot$ Diffusion of innovation $\cdot$ Artificial intelligence $\cdot$ Awareness $\cdot$ Novelty seeking Responsible AI

\section{Introduction}

The Internet of medical things (IoMT) and its advancements (Ghubaish et al., 2021; Giri et al., 2019) are attracted by numerous advantages. Responsible AI when integrated with IoMT offers the world of healthcare and the medical profession multiple benefits which encourage the profession to leave behind existing technologies in favour of IoMT. However, when two new innovations, which are still diffusing and are

Nripendra P. Rana

nrananp@gmail.com

Fatema Al-Dhaen

fsfaldha@bradford.ac.uk

Jiachen Hou

J.Hou1@bradford.ac.uk

Vishanth Weerakkody

v.weerakkody@bradford.ac.uk

1 School of Management, University of Bradford, Richmond Road, Bradford BD7 1DP, UK

2 College of Business and Economics, Qatar University, P.O. Box 2713, Doha, Qatar

3 Faculty of Management, Law and Social Sciences, University of Bradford, Richmond Road, Bradford BD7 1DP, UK not yet fully institutionalised are introduced to a new setting and users are expected to adopt those, concerns arise in the minds of users in regard to the advantage vis-à-vis other similar or equivalent technologies (Ryu, 2018; Choi et al., 2020; de Oca Munguia et al., 2021). Furthermore, in the case of IoMT embedded with AI, which is akin to a new technology embedded in an innovation, more concerns could arise in the minds of users on the extent to which IoMT could be a useful technology aided by AI. The problem becomes complicated when IoMT is still seen to be diffusing (Coventry \& Branley, 2018; Lee \& Yoon, 2021; Safavi \& Kalis, 2019).

The integration of AI into IoMT, while promising to offer many benefits including self-decision making and attempts to replace a human being presents the user and/or organisation with serious risks and an ethical dilemma. This is the case if the decisions made by AI are not accountable and trustworthy (Scott \& Yampolskiy, 2019). A study by Reardon (2019) shows that claims of AI performing better than radiologists were not supported by solid evidence. Here, the concept of responsible AI assumes importance which could include ethical, social and participation concerns including pervasive human/machine interactions that could lead to risks (Dignum, 2017). For instance, challenges related to ethics, social aspects and participation of users while adopting IoMT can lead to a situation wherein it is difficult to control the technology (e.g., information and communication 
technology) on which IoMT is built (Dignum, 2017; Shah \& Chircu, 2018). These aspects could impact healthcare professionals. One aspect of the diffusion of AI based IoMT is that it can impact the continuous intention to use IoMT of healthcare professionals and usage of IoMT (Miraz et al., 2018). Literature shows that while studies concerning behavioural intention to use IoMT continuously have been found, a study of the linkage of the factors or barriers that affect continuous intention to use (the process by which IoMT is accepted and used) IoMT by users is lacking (Lu et al., 2018). Investigation into factors affecting continuous intention to use IoMT could lead to predictability of the continuous intention to use IoMT with responsible AI. Lack of knowledge on the predictability of continuous intention to use behaviour of users of IoMTwith responsible AI can have a devastating effect on the healthcare professionals, patients, hospitals, innovators, suppliers, and manufacturers, which is a key gap in the literature.

While arguing that there could be a linkage between the diffusion factors (predictor) and continuous intention to use IoMT (predicted), this research posits that between the predictor and predicted, there could also be other factors related to behavioural aspects of users that could play a role as argued by DOI (Rogers, 2003). Thus, a research question that needs to be answered is what factors predict the continuous intention to use IoMT directly and indirectly while IoMT is still diffusing? The aim of this research was to investigate the continuous intention to use IoMT by healthcare professionals characterized by responsible AI and factors that affect it. In order to answer this question, the research was conducted in the healthcare sector in Bahrain, a developing economy in the Gulf Cooperation Council (GCC), by studying healthcare professionals who have used or were using IoMT in the work setting. A survey was used to collect data from a representative sample of 276 healthcare professionals in August 2020.

At this point, two assumptions have been made at the core of this research. One is that although IoMT is still an evolving technology, it is possible to investigate the evolution through the prism of diffusion. The second is that factors that encourage the continuous intention to use IoMT are likely to be stronger than those that impede the continuous intention to use it, thus bringing into focus user behaviour towards the usage of IoMT embedded with responsible AI. While the natural instincts of users are more likely to drive them to upgrade existing technology to later versions, hence impeding their continuous intention to use current versions, in the case of IoMT there appears to be compelling factors that could encourage users to continuously use particular versions of the technology. These two assumptions form the basis of this research.

The rest of the paper is organized as follows: The relevant literature reviewed is presented in Section 2 followed by the conceptual model and hypotheses development in Section 3. Section 4 presents the research methodology whereas data analysis in Section 5. Section 6 presents the discussion. Finally, Section 7 presents the conclusion along with limitations and future research directions.

\section{Literature Review}

A review of the extant literature is presented in this section about the factors and barriers affecting the continuous intention to use IoMT. Continuous intention to use as a construct signifies an important aspect of user behaviour and indicates the post-acceptance behaviour of a technology (Zhanyou et al., 2020).

\subsection{Factors Affecting the Continuous Intention to Use IOMT}

According to the literature, the successful and sustained use (continuous intention to use) (Kim et al., 2019) of IoMT is affected by certain factors that are still not well researched (Matheny et al., 2019). Regarding continuous intention to use IoMT, medical professionals are giving mixed signals on its acceptance and continuous use. Some state it is worth using IoMT or any smart device because of the relative advantage it offers in comparison to the existing techniques while others say that it is a complex technology and difficult to use (Mavrogiorgou et al., 2019; Zeadally et al., 2019). The literature shows that IoMT is still evolving, and its use is in its infancy (Kamilaris \& Botteghi, 2020). This indicates that the diffusion of IoMT could be associated with IoMT usage. These examples suggest that a detailed review of the literature could uncover more factors that influence continuous intention to use IoMT. Subsequent examination of the various studies in the literature showed that user intention to continuously use IoMT is a major concern for innovators, manufacturers, suppliers, researchers and technologists (Taylor et al., 2018). While literature shows that there is no certainty on the list of factors or number of factors that affect the continuous intention to use IoMT, the outcome of some studies is showing encouraging results in this regard. For instance, user attitudes, motivations and behaviours (Abildgaard et al., 2016), training (Saarikko et al., 2017), the relative advantage of IoMT, the complexity of IoMT, compatibility of IoMT, trialability of IoMT, observability of IoMT (Al-Rahmi et al., 2019), awareness about AI (Mansour et al., 2019), age (Venkatesh et al., 2012) and novelty-seeking behaviour (Tsao \& Yang, 2017) were found to be some of the factors identified in the literature as affecting continuous intention to use IoMT embedded with responsible AI. However, research in these studies do not address the issue of IoMT embedded with responsible AI when both are diffusing concurrently and the interaction amongst those factors in one holistic model. This research addresses this issue. 


\subsection{Barriers Affecting the Continuous Intention to Use IoMT}

Research has found that several barriers affect the continuous use of IoMT by healthcare professionals in supporting patients and such barriers need to be removed if IoMT usage has to be improved. Literature shows that barriers to the usage of IoT and therefore IoMT, include illiteracy on the part of the user related to technology, failure of technology due to its poor management, and the high level of training needed (Nijeweme-d'Hollosy et al., 2015). Other barriers include lack of awareness, lack of value perception of customers, behavioural challenges, cost, security, handling new technology, lack of qualified workforce and employee resistance (Ericsson, 2015; Padyab et al., 2019; Winchcomb et al., 2017). Despite such barriers, if users continue to use IoMT then the use of IoMT by both patients and patient-care providers could not be considered as an automatic occurrence. In fact, literature shows that a study of the linkage of the factors or barriers that affect continuous intention to use (the process by which IoMT is accepted and used) IoMT to continuous intention to use IoMT by users is lacking (Lu et al., 2018).

In order to address the above issues and taking into account the utility and applicability of DOI for this research, five factors of innovation diffusion, namely, relative advantage, compatibility, complexity, observability and trialability become the main focus of this research. They are conceived as the determinants of the behavioural intention of the use of IoMT-with responsible AI - by healthcare professionals. In addition to this, some researchers (Baudier et al., 2019; Lee et al., 2005; Van der Heijden, 2004; Venkatesh et al., 2002) have argued that motivation is an important aspect in the usage of technology, continuous intention to use technology or behavioural intention to use technology, an argument which could be extended to IoMT usage. It is argued further that better understanding of the motivation of people concerned with usage or behavioural intention to use technology including IoT and IoMT could be useful in improving the usage or behavioural intention to use IoMT, knowledge about which is not clear in the literature (Baudier et al., 2019). This is an important gap in the literature which if addressed is expected to bring out new knowledge on how to motivate users to use IoMT and enhance the usage of IoMT-with responsible AI to the betterment of patient care. Similarly, another factor that was considered essential to this research was training in IoMT. It was argued in the literature (Ozkeser, 2019) that training is nearly an inseparable part of IoMT and an associate factor of the motivation of users. Innovations in IoMT involve complex technologies and understanding on how to use them over a long term requires the support of technicians who can help healthcare professionals to develop the needed skills to use IoMT devices through training. However, literature shows that there is a lack of knowledge and research outcomes on how training in IoMT as a concept has to be understood with regard to the use of technologies and new technologies (AlGahtani, 2016; Gaynor et al., 2015) especially so with regard to a currently diffusing technology. To what extent motivation and its associated concept of training in IoMT affect acceptance of IoMT and its use after acceptance, when it is still diffusing, is not well understood in the literature as hardly any research publication addressing this aspect can be found in the literature.

\subsection{Effect of Responsible Al on loMT}

IoMT is a fairly new concept and is considered a novel idea (Rodrigues et al., 2018) and is combined with responsible AI that is constantly reshaping services (Huang \& Rust, 2018). Literature (Sugandini et al., 2018) shows that the perceived behaviour of users of new or novel products is significantly affected by the new product trial. IoMT associated with responsible AI being a new and novel concept, this factor is also considered as important for this research as a moderator of the relationship between antecedents of continuous intention to use IoMT, and continuous intention to use IoMT. If one argues that technology is a phenomenon that affects any field including IoMT, it is inevitable that awareness about the impact of those technologies on the users becomes a major concern. This is due to the tendency of technological innovations being more complex and a lack of awareness about using those technologies could pose a challenge (Chen et al., 2020). This is echoed by Gómez-González et al. (2020) who argue that $\mathrm{AI}$ and $\mathrm{AI}-$ mediated technologies in medicine and healthcare need to be studied concerning principles, ethical and societal guidelines, and potential boundaries, as these areas are challenging and responses to those challenges are not yet well developed.

\section{Theoretical Background, Conceptual Model and Hypotheses Development}

\subsection{Theoretical Background}

Common examples of theories that have been used by researchers to predict acceptance and usage of new technological innovations found in the literature include the theory of reasoned action (TRA) (Buabeng-Andoh et al., 2019), the theory of planned behaviour (TPB) (Li et al., 2020), technology acceptance model (TAM) (Deng et al., 2018), DOI (Mohammadi et al., 2018), task technology fit (TTF) (Shahbaz et al., 2019) and unified theory of acceptance and use of technology (UTAUT) (Alam et al., 2018). Continuous use of IoMT or behavioural intention of users of IoMT-with responsible AI is not easy to predict because of the involvement of many different factors that affect users although DOI 
has been shown to have the ability to clarify behavioural aspects of users in relation to innovation and its diffusion, according to a crucial study by Rogers (2003).

DOI talks about innovation and how it diffuses across the users and brings into focus the need to understand the adopter and the adopted (Rogers, 2003). But it talks about only a single innovation that diffuses at a single point of time and is accepted once. While literature shows that the phenomenon of diffusion of innovation cannot be substituted with other theories. At the same time diffusion cannot also explain all the reasons why people adopt an innovation or how the innovation diffuses (Taherdoost, 2018). In contrast, the speed with which an innovation penetrates a market and is adopted could not be explained by such theories as TRA, TPB, TAM and UTAUT (Fry et al., 2018). One of the reasons for this is that these four theories focused on the adopter and the people surrounding the adopter which is linked to their perception and intentions. In addition, the base for TPB and TAM is the TRA while UTAUT is a more complex model that depends on eight different models. It was therefore concluded that the nearest theory that can be seen to support this study is the DOI and hence this theory has been used as the base for this research. Despite its limitation on how certain repetitions of an innovation diffuse or fail to diffuse, it was thought worthwhile to apply this theory to understand how an innovation like IoMT or its subsequent manifestation will be accepted and continuously used by healthcare professionals.

It is important to understand whether an innovation like IoMT is likely to be accepted and used by the users' midstream through the different stages of the diffusion of the innovation or after the innovation has fully diffused and resulted into continuous use. An understanding of this at multiple stages provides an opportunity to maintain the quality of the innovation or improve the features of innovation or drop the innovation and eventually predict its acceptance and continued use.

\subsection{Proposed Conceptual Model}

The focus of the present study is on how to predict the continuous intention to use IoMT. From the literature review, three sets of factors have been identified as affecting the continuous intention to use IoMT. The first set of factors are diffusion factors. Literature shows that the perception of relative advantage, compatibility, complexity, observability and trialability of the technology of the users can influence the continuous intention to use technology (Rogers, 2003).

The second set of factors include intervention factors. Motivation is expected to be generated by the ease of use and usefulness of IoMT. Similarly, a lack of training could be a threat to the users of IoMT (Saarikko et al., 2017) and hence identified as a driver of continuous use of IoMT during the process of diffusion. Here it must be mentioned that usage implies continuous intention to use following the first use of technology and maintain such usage of technology (Pang et al., 2020).

The third set of factors included moderating factors. Age and novelty-seeking behaviour were argued to be the moderators of the relationships motivation-continuous intention to use and training-continuous intention to use (Dabholkar \& Bagozzi, 2002; Um et al., 2020). Additionally, awareness of AI was posited to moderate the relationships such as the relative advantage (of IoMT)-motivation (to use IoMT), the relative advantage, training (to use IoMT), complexity (of IoMT)motivation, complexity (of IoMT)-training, compatibility (of IoMT)-motivation and compatibility of IoMT-training Chen et al., 2020). The above discussions thus led to the resulting model provided in Fig. 1.

\subsubsection{Relative Advantage $\rightarrow$ (Motivation, Training)}

Using DOI the relationship between the relative advantage, training, and the intrinsic motivation of an individual to use IoMT can be established. The relative advantage creates a sense of autonomy in an individual and influences the intrinsic motivation of individuals to use IoMT (Jaleel et al., 2020). Similarly, Park and Choi (2019) argue that training represents organizational factors and can be used as a determinant of the information technology innovation behavioural intention to use IoMT alongside DOI components. Therefore, the following can be hypothesised:

H1a: Relative advantage positively influences motivation.

H1b: Relative advantage positively influences training.

\subsubsection{Complexity $\rightarrow$ (Motivation, Training)}

If an innovation is complex, researchers have used different ways to reduce complexity to motivate users. Hardgrave et al. (2003) found out that complexity has a negative relationship with perceived usefulness, a construct of motivation. Similarly, Tristani et al. (2020) argued that more users will embark on training, using learning materials if the material is less complex. That is to say, the complexity and training in IoMT are related. Based on the arguments, the following is hypothesised:

H2a: Complexity negatively influences motivation. $\mathrm{H} 2 \mathrm{~b}$ : Complexity positively influences training.

\subsubsection{Compatibility $\rightarrow$ (Motivation, Training)}

Innovation adoption rate is related to the degree of compatibility (AlSheibani et al., 2020). Further, if two IoMT devices 
Fig. 1 Proposed Research Model (Source: Adapted from Rogers, 1995)

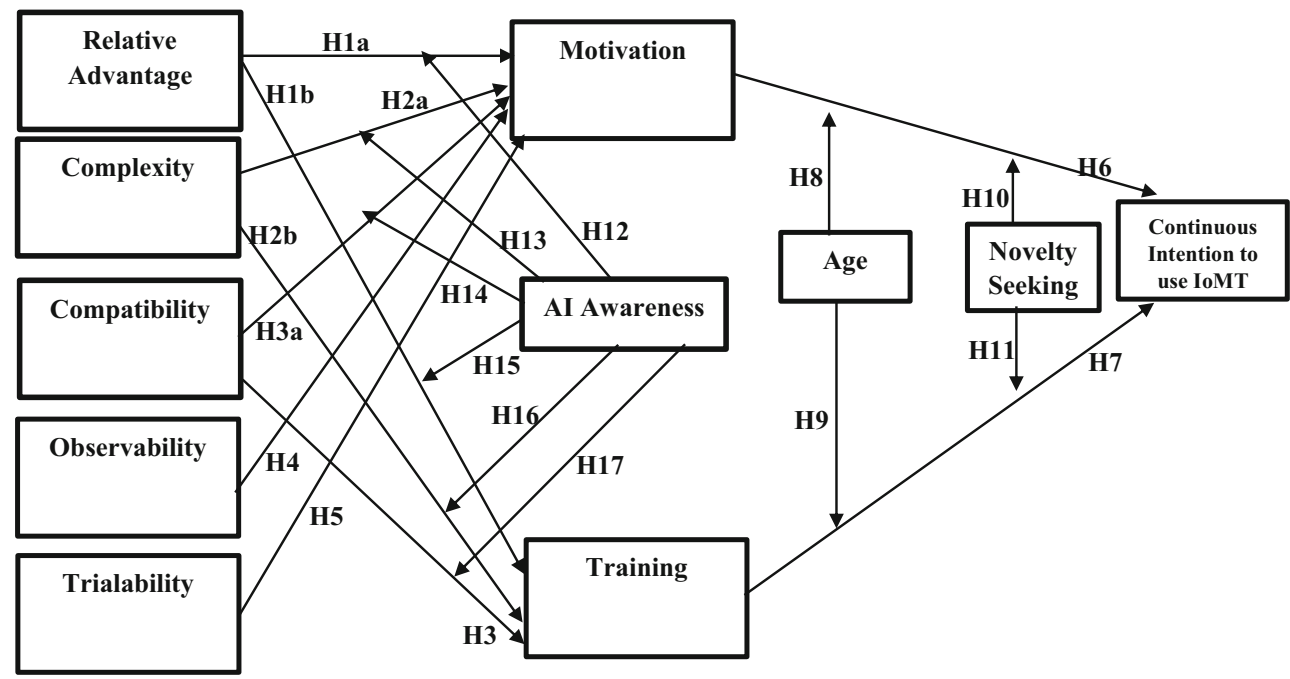

are compatible then the perceived ease of use (synonymous to motivation) (Bastari et al., 2020) could be positively influenced (Agarwal \& Prasad, 1999). Additionally, incompatibility could be reduced by training. Thus, replacing perceived ease of use by motivation, the following could be hypothesised:

H3a: Compatibility positively influences motivation.

H3b: Compatibility positively influences training:

\subsubsection{Observability $\rightarrow$ Motivation}

Observability of innovation is defined as an innovation's outcome which shows that innovation is noticeable to others (Rogers, 2003; Al-Rahmi et al., 2019;) and is explained by DOI. Taking the recommendations of Al-Rahmi et al. (2019) it is posited that observability (of IoMT) influences motivation. Therefore, we propose the following hypothesis:

H4: Observability positively influences motivation.

\subsubsection{Trialability $\rightarrow$ Motivation}

Literature shows that trialability (of IoMT) as a diffusion factor affects the motivation of users of the innovation (Al-Rahmi et al., 2019). Based on the arguments of Rogers (2003) and Chiyangwa and (Trish) Alexander (2016) it is posited that success of trialability could reduce uncertainty about IoMT and speedy adoption. Therefore, we propose the following hypothesis:

H5: Trialability positively influences motivation to use IoMT.

\subsubsection{Motivation $\rightarrow$ Continuous Intention to Use loMT}

Motivation is a personal characteristic and has been found to play an important role in many technologies and innovations' continuous intention to use IoMT and usage related concepts (Franke et al., 2006; Hang \& Kau, 2016; Marzouki \& Belkahla, 2019). This was tested as there is no compelling evidence in the literature to establish this. Therefore, we propose the following hypothesis:

H6: Motivation positively influences continuous intention to use IoMT.

\subsubsection{Training $\rightarrow$ Continuous Intention to Use loMT}

Literature shows there is a lack of knowledge on how training in IoMT as a concept has to be understood with regard to the use of new technologies (Gaynor et al., 2015; Al-Gahtani, 2016;) including a diffusing technology. Further, where the motivation of individuals is involved, then training becomes an automatic choice, as training is considered to be an associate construct of motivation (Bhatti et al., 2013). Therefore, we propose the following hypothesis:

H7: Training positively influences continuous intention to use IoMT.

\subsubsection{Age as a Moderator of Relationship between Motivation, Training, and Continuous Intention to Use}

That age can act as a moderator of relationships in a model that concerns the intention to use technology is supported by UTAUT (Venkatesh et al., 2012). As early as the late nineties 
of the previous century Chau and Hui (1998) argued that when an innovation is in its beginning stages of diffusion, younger people are likely to exhibit a greater tendency to seek innovativeness when compared to older people. Similarly, it is posited that IoT solutions must be associated with training in order to ensure its effective usage (McRae et al., 2018) including IoMT. Therefore, we propose the following hypotheses:

H8: Age moderates the relationship between motivation to use and continuous intention to use IoMT.

H9: Age moderates the relationship between training and continuous intention to use IoMT.

\subsubsection{Novelty Seeking as a Moderator of the Relationship between Motivation, Training, and Continuous Intention to Use}

It is argued in the literature (Venkatesh et al., 2012) that novelty seeking behaviour affects the motivation of people and drives the continuous intention to use the technology of users of innovation. Further, by using UTAUT it can be argued that the relationship between facilitating conditions (e.g., training) and intention to use can also be moderated by novelty seeking behaviour of users (Venkatesh et al., 2012). Therefore, we propose the following hypotheses:

H10: Novelty seeking positively moderates the relationship between motivation and continuous intention to use IoMT.

H11: Novelty seeking positively moderates the relationship between training and continuous intention to use IoMT.

\subsubsection{Al Awareness as a Moderator of the Relationship between DOI Constructs and Motivation}

IoMT while diffusing is affected by awareness about technology (Leal \& Albertin, 2015). Further, the relative advantage of $\mathrm{AI}$ in IoMT is the predictability of risk and presence or absence of a disease in an individual (Matheny et al., 2019). When supported by awareness about AI, it could encourage (motivate) users to continuously use IoMT, as AI could reduce the complexities involved in predicting risk and presence or absence of a disease in individuals. Similarly, AI awareness could help IoMT users, for instance, individuals and organisations, who are small and relatively unsophisticated (Matheny et al., 2019) to overcome complexity related challenges concerning IoMT. Finally, compatibility concerns, for instance interoperability concerns of IoMT devices, could be a major problem for the usage of IoMT (Jaleel et al., 2020). Therefore, Chen et al. (2020) argue that AI awareness is necessary for AI adoption which implies that embedding responsible AI in IoMT needs to be supplemented by AI awareness. Therefore, we propose the following hypotheses:

H12: AI awareness positively moderates the relationship between relative advantage and motivation.

H13: AI awareness positively moderates the relationship between complexity and motivation.

H14: AI awareness positively moderates the relationship between compatibility and motivation.

\subsubsection{Al Awareness as a Moderator of the Relationship between DOI Constructs and Training to Use}

Training has been already posited to be influenced by the relative advantage in an earlier section. It is also posited that the relationship relative advantage -motivation can be moderated by AI awareness and can be linked to training as motivation is concerned with training (Miao et al., 2020). Next, Chen et al. (2020) argues that training in AI and awareness in AI created due to training can enhance usage intentions reducing complexities. Finally, AI should be compatible with the organisational environment, which in this study is AI embedded in IoMT in a healthcare setting. Therefore, we propose the following hypotheses:

H15: AI awareness positively moderates the relationship between relative advantage and training.

H16: AI awareness positively moderates the relationship between complexity and training.

H17: AI awareness positively moderates the relationship between compatibility and training.

\section{Research Methodology}

The research was conducted in Bahrain. As far as healthcare is concerned, Bahrain has well-equipped hospitals both in the public and private sectors with 19 hospitals and 746 registered health care facilities operating by the end of 2019 (NHRA, 2019). The healthcare system in Bahrain is very similar to the NHS in the UK. The Internet of healthcare things (synonymous to IoMT) is already being used in the healthcare sector (Haji, 2018) with such devices as wearables widely being used by citizens and their health tracked through the internet by healthcare professionals. All hospitals involved in this research were provided with the ethical approval granted by University of Bradford, which enabled the researcher to mitigate challenges concerning access to subjects who could participate in the research. 


\subsection{Data Collection}

It was pertinent to approach research respondents who were knowledgeable about the phenomenon under investigation. Thus, respondents who have experiences of using IoMT were selected, to provide rich, diverse, and holistic views. A selfadministered questionnaire (Appendix B) was developed to collect data through an online survey, by adapting already validated instruments found in the literature. Only closed and multiple-choice questions were included in the questionnaire. The list of healthcare professionals accessed to get responses and their percentage is provided in Table 1.

Section A in the survey instrument was used to collect the demographic information related to gender, age, professional status, education level and the familiarity of the participants with regard to IoMT. Section B in the survey instrument consisted of 49 items that were used to measure the independent and dependent variables (Table 2).

\subsection{Survey Protocol}

A survey protocol was developed to ensure that the process of generating the data was structurally sound. The items were measured using 5-point Likert scales with 1 indicating 'strongly disagree' 2 indicating 'disagree', 3 indicating 'neutral', 4 indicating 'agree' and 5 indicating 'strongly agree'. Appendix B lists the items used to measure the variables. Random sampling was used to collect data. The total population of healthcare professionals who are available in Bahrain was estimated to be over 15,000. The sample size worked out to be 375 at a confidence level of $95 \%$ and a confidence interval of $5 \%$. Considering the fact that the minimum sample size of participants from whom data needs to be collected was calculated as 375, a little over 500 respondents were approached with the support of many hospitals in Bahrain. To maintain anonymity, the names of the hospitals have not been mentioned in this paper. 276 responses were received which is a response rate of $55.2 \%$. Sekaran and Bougie (2016) recommend that a response rate of $30 \%$ is acceptable in most research efforts using a survey. Eight responses were rejected as the responses were not complete. Thus, the final number of useful responses stood at 268. Another 34 responses were rejected as outliers. Outliers were detected using Mahalanobis distance and were deleted. Table 2 shows the details of the demography of the participants. In addition, descriptive statistics are provided in Table 3. The standard deviation for all items was found to be less that \pm 1.5 indicating the normal distribution of data.

\section{Findings}

The analysis was conducted using SPSS and AMOS version 21.0. This constitutes of two steps including the confirmatory factor analysis and the structural model analysis.

\subsection{Confirmatory Factor Analysis}

SPSS (Version 21) was used to analyse reliability of the instrument and the scale. Cronbach's alpha is a widely used test to determine the reliability of the scale and provides an estimate of the internal consistency of the items used to measure the constructs (Cronbach, 1946; Sekaran \& Bougie, 2016). Sekaran and Bougie (2016) explain that an alpha value $>0.7$ is considered to be acceptable.

The internal consistency measurements showed that item to item correlations and item to total correlations were acceptable for all constructs with the minimum for any construct found to
Table 1 List of healthcare professionals who participated in the survey

\begin{tabular}{lll}
\hline Occupation of healthcare professionals & $\#$ & \% \\
\hline Hospital doctors & 29 & 10.51 \\
Community Health Services doctors & 1 & 0.36 \\
Consultant doctors & 45 & 16.30 \\
General practitioners & 20 & 7.25 \\
Allied healthcare professional & 30 & 10.87 \\
Pharmacist & 13 & 4.71 \\
Healthcare scientist (e.g., cervical cytology screener, phlebotomist, new-born hearing screener & 3 & 1.09 \\
$\quad$ and healthcare science assistant/associate) & 75 & 27.17 \\
Nurses and Health Visitors & 1 & 0.36 \\
Ambulance staff & 27 & 9.78 \\
Other GP Practice staff (direct patient care) (e.g., other staff involved in providing direct patient & 27 \\
$\quad$ care, which includes clinical pharmacists, dispensers, phlebotomists, therapists, healthcare & & \\
assistants and others). & 32 & 11.59 \\
Other GP Practice staff (admin) (e.g., Receptionist and administrative staff) & 276 & 100.00 \\
Total & & \\
\hline
\end{tabular}


Table 2 Demographic characteristics of respondents

\begin{tabular}{|c|c|c|c|}
\hline Variables & Specification & Frequency & Valid Percent \\
\hline \multirow[t]{3}{*}{ Gender } & Male & 160 & 60.4 \\
\hline & Female & 90 & 33.6 \\
\hline & Prefer not to say & 16 & 6 \\
\hline \multirow[t]{5}{*}{ Age } & $18-25$ & 23 & 8.6 \\
\hline & $26-33$ & 88 & 32.8 \\
\hline & $34-41$ & 59 & 22 \\
\hline & $42-49$ & 43 & 16 \\
\hline & Over 50 & 55 & 20.5 \\
\hline \multirow[t]{4}{*}{ Usage } & Using IoMT currently & 69 & 25.7 \\
\hline & Aware of IoMT & 77 & 28.7 \\
\hline & Intend to use IoMT in future. & 30 & 11.2 \\
\hline & Not familiar with IoMT & 92 & 34.3 \\
\hline \multirow[t]{5}{*}{ Education } & High school graduate or equivalent & 6 & 2.2 \\
\hline & Bachelor's degree & 129 & 48.1 \\
\hline & Master's degree & 64 & 23.9 \\
\hline & Professional certificate & 48 & 17.9 \\
\hline & Doctorate & 21 & 7.8 \\
\hline \multirow[t]{11}{*}{ Occupation } & Hospital doctors & 28 & 10.4 \\
\hline & Community Health Services doctors & 1 & 0.4 \\
\hline & Consultant doctors & 45 & 16.8 \\
\hline & General practitioners & 19 & 7.1 \\
\hline & Allied healthcare professional & 28 & 10.4 \\
\hline & Pharmacist & 12 & 4.5 \\
\hline & Healthcare scientist & 3 & 1.1 \\
\hline & Nurses and Health Visitors & 72 & 26.9 \\
\hline & Ambulance staff & 1 & 0.4 \\
\hline & Other GP Practice staff (direct patient care) & 27 & 10.1 \\
\hline & Other GP Practice staff (admin & 32 & 11.9 \\
\hline
\end{tabular}

be 0.397 and 0.536 , respectively. One item (NS5: "I do not like meeting IoMT service providers who have new ideas about IoMT") measuring the construct novelty seeking was found to cause correlational problems and was deleted. The convergent validity was established through the inter-item correlation and item to total correlation which according to Robinson et al. (1991) should be greater than 0.3 and 0.5 , respectively. The descriptive statistics showed that the standard deviation figures of all the items were within \pm 2.0 indicating that the responses were normally distributed. Structural Equation Modelling (SEM) was used to analyse the data to test the hypotheses and answer the research question. This is a widely used technique that is used to estimate a set of interrelated dependence relationships simultaneously (Hair et al., 2006). The confirmatory factor analysis led to the final structural model given in Fig. 2. Fitness of the CFA model to data was tested using Comparative Fit Index (CFI), Incremental Fit Index (IFI) and Root Mean Square Error of Approximation (RMSEA). According to literature there is no specific number of indices that need to be tested and reported (Schermelleh-
Engel et al., 2003). However, Karakaya-Ozyer and AksuDunya (2018) recommend that it is important to report as many model fit indices as possible although the choice of the fit indices is left to the researchers. According to Schreiber et al. (2006) minimum values of CFI and IFI considered as acceptable is $>0.9$. According to Hooper et al. (2008) acceptable values of RMSEA lie between 0.05 and 0.1 (Gul \& NezamiFar, 2020). The fit indices derived from AMOS were CFI $=0.905$; IFI $=0.906$; and RMSEA $=$ 0.074 (see Table 4).

\subsection{Applying the Structural Model}

The structural model is provided in Fig. 1. The structural model was used to test the relationship between the exogenous (relative advantage, complexity, compatibility, trialability and observability) and endogenous variables (motivation, training, and continuous intention to use IoMT). The moderation variables were not included in the structural model. The analysis of the 
Table 3 Alpha, mean and standard deviation of constructs

\begin{tabular}{|c|c|c|c|c|}
\hline Construct & Cronbach's alpha & Items & Mean & S.D. \\
\hline \multirow[t]{6}{*}{ Relative advantage } & \multirow[t]{6}{*}{0.950} & RA1 & 3.7039 & 1.11913 \\
\hline & & RA2 & 3.6609 & 1.11459 \\
\hline & & RA3 & 3.7124 & 1.10978 \\
\hline & & RA4 & 3.5923 & 1.06728 \\
\hline & & RA5 & 3.4764 & 1.11053 \\
\hline & & RA6 & 3.5150 & 1.10289 \\
\hline \multirow[t]{3}{*}{ Complexity } & \multirow[t]{3}{*}{0.854} & $\mathrm{CPX} 2$ & 2.5279 & 1.06688 \\
\hline & & CPX3 & 2.6137 & 1.08126 \\
\hline & & $\mathrm{CPX} 4$ & 2.6824 & 1.07177 \\
\hline \multirow[t]{4}{*}{ Compatibility } & \multirow[t]{4}{*}{0.837} & CMP1 & 3.1760 & 1.02928 \\
\hline & & CMP2 & 3.2618 & 1.04020 \\
\hline & & CMP3 & 3.4635 & 1.00417 \\
\hline & & CMP4 & 3.3820 & 0.95368 \\
\hline \multirow[t]{4}{*}{ Trialability } & \multirow[t]{4}{*}{0.848} & TRI1 & 2.8755 & 1.12838 \\
\hline & & TRI2 & 2.9442 & 1.11470 \\
\hline & & TRI3 & 2.9571 & 1.16628 \\
\hline & & TRI4 & 2.7639 & 1.12575 \\
\hline \multirow[t]{3}{*}{ Observability } & \multirow[t]{3}{*}{0.801} & OBS1 & 3.0730 & 1.12908 \\
\hline & & OBS3 & 3.0086 & 1.11026 \\
\hline & & OBS4 & 2.9528 & 1.13426 \\
\hline \multirow[t]{5}{*}{ Training } & \multirow[t]{5}{*}{0.948} & TRN1 & 3.0429 & 1.08986 \\
\hline & & TRN2 & 3.1288 & 1.10668 \\
\hline & & TRN3 & 3.2833 & 1.15091 \\
\hline & & TRN4 & 3.2403 & 1.13438 \\
\hline & & TRN5 & 3.2403 & 1.09965 \\
\hline \multirow[t]{4}{*}{ Motivation } & \multirow[t]{4}{*}{0.916} & MOT1 & 3.5966 & 1.09481 \\
\hline & & MOT3 & 3.4034 & 1.05061 \\
\hline & & MOT4 & 3.4721 & 1.05059 \\
\hline & & MOT5 & 3.4378 & 1.10514 \\
\hline \multirow[t]{4}{*}{ Continuous intention to use IoMT } & \multirow[t]{4}{*}{0.922} & CI1 & 3.7210 & 1.13119 \\
\hline & & CI2 & 3.7983 & 1.11324 \\
\hline & & $\mathrm{CI} 3$ & 3.7082 & 1.01742 \\
\hline & & CI4 & 3.7339 & 1.08179 \\
\hline
\end{tabular}

influence of moderating variables age, AI awareness and novelty seeking on the different relationships were separately tested using AMOS. The construct reliability was established by the squared multiple correlation
(SMC) with all values found to be greater than 0.3 which is recommended by Holmes-Smith ssset al., (2006). Discriminant validity was established using sample correlations. Correlations between latent constructs
Table 4 Fit indices for measurement model

\begin{tabular}{lll}
\hline Fit statistics & Recommended value & Measured value \\
\hline Chi-square/ Degree of Freedom (CMIN/DF) & $<3.000$ & 2.274 \\
Probability value (p) & $>0.05$ & 0.000 \\
Incremental fit index (IFI) & $\geq 0.9$ & 0.906 \\
Comparative fit index (CFI) & $\geq 0.9$ & 0.905 \\
Root mean square error of approximation (RMSEA) & $\leq 0.080$ & 0.074 \\
\hline
\end{tabular}


Fig. 2 Structural model with regression weights

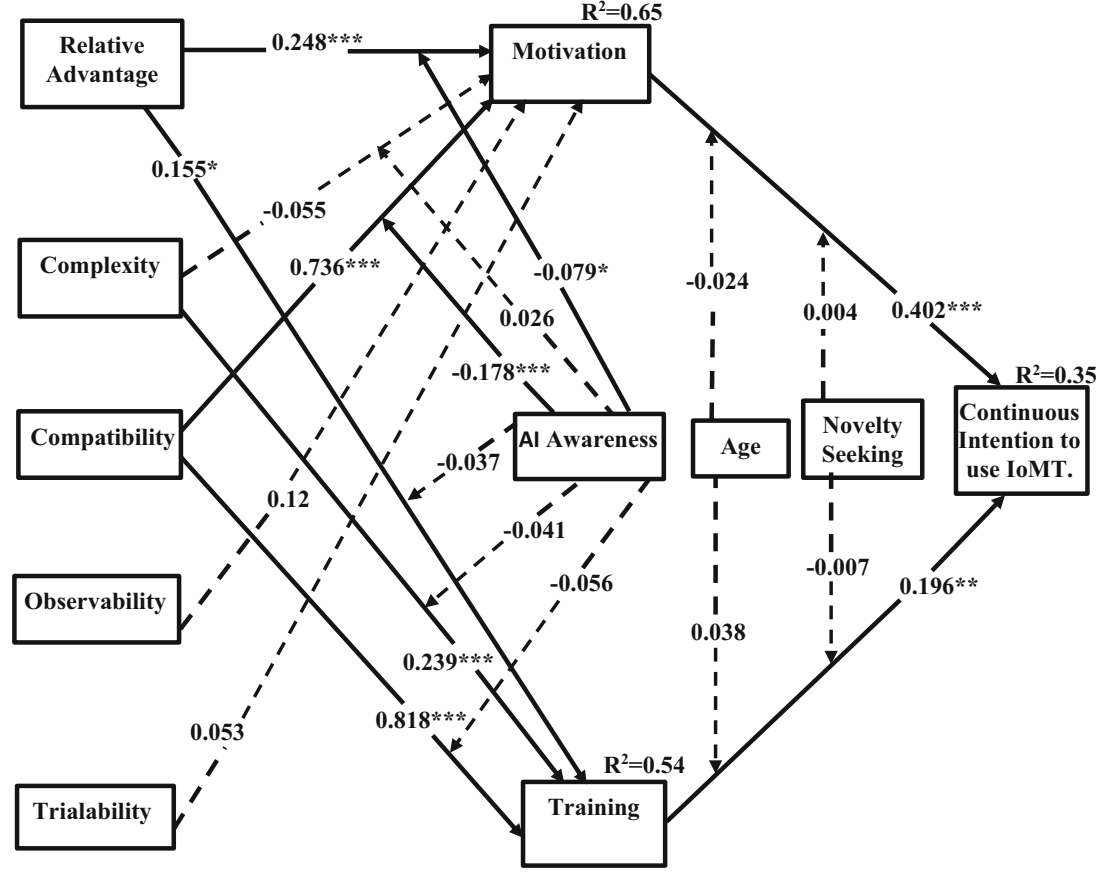

or observed variables (items) higher than 0.80 or 0.90 suggest the presence of discriminant validity (HolmesSmith et al., 2006). The highest value of correlation (0.893) was found between the two items TRN4 and TRN5. Thus, discriminant validity was established.

Final valid relationships are provided by the AMOS output provided in Table 5. Fitness of the model was tested using CFI, IFI and RMSEA (Table 6).

After checking the fitness of the model, the next test conducted was the average variance extracted test which provides another measure of discriminant validity as well as indicates the presence or absence of method bias. The results presented in Table 7 show that the discriminant validity extracted for all the constructs has been achieved.

\subsection{Moderation Effect by Al Awareness}

Moderation of the various paths by AI awareness was tested using AMOS. The following example provides the method used.

AI Awareness moderating the relationship Relative Advantage $\rightarrow$ Motivation

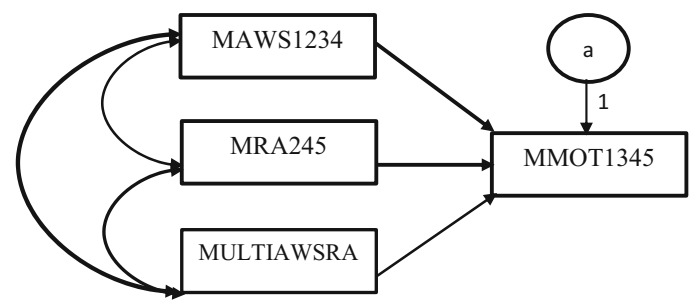

Fig. 3 Moderation effect of AI Awareness

\subsection{Al Awareness moderating the relationship of Relative Advantage $\rightarrow$ Motivation}

Here MMOT1345 indicates the mean of the items measuring the construct motivation, MAWS1234 indicates the mean of the items measuring the construct AI Awareness, MRA245 indicates the mean of the items measuring the construct relative advantage and MULTIAWSRA indicates the multiplication of MAWS1234 and MRA245. In order to test the moderation effect of AI Awareness on the relationship between Relative Advantage and Motivation, the influence of the variables MAWS1234, MRA245 and MULTIAWSRA on the construct motivation was measured using AMOS. The regression weights report of AMOS is provided in Table 7. The main parameter of interest was the $\mathrm{p}$ value of the product term MULTIAWSRA. Table 8 shows that the $p$ value is less than 0.05 indicating that the influence of the product term on motivation is statistically significant. Thus, the hypothesis H15 is accepted. Table 9 shows the explanation of the coding adopted in this research with regard to moderators. A similar test was conducted to verify the moderation effect of AI Awareness on other paths, the results of which are provided in Table 10.

\subsection{Moderation Effect by Novelty Seeking and Age}

Novelty seeking behaviour of users of IoMT was not found to influence the relationship between motivation and training to use IoMT on the one hand and continuous intention to use IoMT on the other. This was revealed when novelty-seeking behaviour was used as a moderating variable of the 
Table 5 List of hypotheses accepted and rejected

\begin{tabular}{|c|c|c|c|c|c|c|c|}
\hline \multicolumn{3}{|l|}{ Path relationship } & \multirow{2}{*}{$\begin{array}{l}\text { Path coefficient } \\
0.248\end{array}$} & \multirow{2}{*}{$\begin{array}{l}\mathrm{p} \text { value } \\
* * *\end{array}$} & \multirow{2}{*}{$\begin{array}{l}\text { Accepted hypotheses } \\
\text { H1a }\end{array}$} & \multirow{2}{*}{$\begin{array}{l}\text { Dependent Variable } \\
\text { Motivation }\end{array}$} & \multirow{2}{*}{$\begin{array}{l}\mathrm{R}^{2} \\
0.65\end{array}$} \\
\hline Motivation & $<--$ & Relative advantage & & & & & \\
\hline Training & $<--$ & Complexity & 0.239 & $* * *$ & $\mathrm{H} 2 \mathrm{~b}$ & Training & 0.54 \\
\hline Motivation & $<---$ & Compatibility & 0.736 & $* * *$ & $\mathrm{H} 3 \mathrm{a}$ & Continuous intention to use & 0.35 \\
\hline Training & $<--$ & Relative advantage & 0.155 & .023 & $\mathrm{H} 1 \mathrm{~b}$ & & \\
\hline Training & $<---$ & Compatibility & 0.818 & $* * *$ & $\mathrm{H} 3 \mathrm{~b}$ & & \\
\hline Continuous intention to use & $<---$ & Motivation & 0.402 & $* * *$ & H6 & & \\
\hline \multirow[t]{2}{*}{ Continuous intention to use } & $<--$ & Training & 0.196 & 0.002 & $\mathrm{H} 7$ & & \\
\hline & & & & & Rejected hypotheses & & \\
\hline Motivation & $<---$ & Complexity & -.055 & 0.320 & $\mathrm{H} 2 \mathrm{a}$ & & \\
\hline Motivation & $<---$ & Trialability & .053 & 0.597 & $\mathrm{H} 4 \mathrm{a}$ & & \\
\hline Motivation & $<---$ & Observability & 0.12 & 0.28 & $\mathrm{H} 5 \mathrm{a}$ & & \\
\hline
\end{tabular}

***indicates that the regression weight for the predictor in the predicted is significantly different from zero at the 0.001 level (two-tailed)

relationship between motivation and training on the one hand and continuous intention to use IoMT on the other, using AMOS as in the case of AI Awareness. The results of the regression showed that there was no statistical significance found when the product terms (mean novelty-seeking * mean of motivation) and (mean of novelty-seeking * mean of training) were regressed with continuous intention to use. Thus, hypotheses H10 and H11 were rejected. Through the same process, it was found that age did not moderate the relationships (motivation) $\rightarrow$ (Continuous intention to use IoMT) and (training) $\rightarrow$ (Continuous intention to use IoMT). Thus, hypotheses $\mathrm{H} 8$ and $\mathrm{H} 9$ were rejected.

\subsection{Total Effect of Independent Variables on Dependent Variables}

The total effect of independent variables on the dependent variables through different paths provide an idea about the influence exerted by the independent variables on the dependent variable. It also enables an understanding of the predictability of the continuous intention to use IoMT (Table 11).

The finally specified model that has been tested fully is provided in Fig. 2. The solid lines indicate the accepted relationships while the broken lines indicate the rejected relationships. Thus, in the final model it can be seen that only 9 hypotheses have been accepted.

\section{Discussion}

The main aim of this research was to investigate the continuous intention to use IoMT by healthcare professionals characterized by responsible AI and factors that affect it. IoMT is an innovation of recent times and is still evolving (Kamilaris \& Botteghi, 2020). The theory of DOI was applied to explain the phenomenon of continuous intention to use IoMT. DOI explained the diffusion of two interrelated innovations namely IoMT embedded with responsible AI.

The relative advantage drives motivation and training, which in turn influences continuous intention to use IoMT positively. For instance, IoMT can help in remote monitoring of patient health. Healthcare professionals are often constrained to be at the place of the patient due to many factors including culture, language barrier, accessibility, and workload (Al-Hadban et al., 2017; Jacob et al., 2020). Additionally, training in IoMT will help healthcare professionals to deliver better healthcare which in turn is expected to motivate them, an
Table 6 Fit indices for structural model

\begin{tabular}{lll}
\hline Fit statistics & Recommended value & Measured value \\
\hline Chi-square/ Degree of Freedom (CMIN/DF) & $<3.000$ & 2.427 \\
Probability value (p) & $>0.05$ & 0 \\
Incremental fit index (IFI) & $\geq 0.9$ & 0.915 \\
Comparative fit index (CFI) & $\geq 0.9$ & 0.914 \\
Root mean square error of approximation (RMSEA) & $\leq 0.080$ & 0.078 \\
\hline
\end{tabular}


Table 7 Discriminant validity

\begin{tabular}{lllllllll}
\hline & RA & CMP & TRI & CI & OBS & TRN & MOT & CPX \\
\hline RA & $\mathbf{0 . 8 2 6}$ & & & & & & & \\
CMP & 0.310 & $\mathbf{0 . 6 1 5}$ & & & & & & \\
TRI & 0.180 & 0.236 & $\mathbf{0 . 6 1 9}$ & & & & & \\
CI & 0.585 & 0.284 & 0.171 & $\mathbf{0 . 7 7 3}$ & & & & \\
OBS & 0.143 & 0.259 & 0.428 & 0.132 & $\mathbf{0 . 6 5 0}$ & & & \\
TRN & 0.240 & 0.345 & 0.401 & 0.205 & 0.561 & $\mathbf{0 . 8 3 2}$ & & \\
MOT & 0.368 & 0.445 & 0.229 & 0.261 & 0.259 & 0.355 & $\mathbf{0 . 8 0 5}$ & \\
CPX & 0.001 & 0.014 & 0.063 & 0.000 & 0.045 & 0.063 & 0.003 & $\mathbf{0 . 6 6 4}$ \\
\hline
\end{tabular}

argument supported by $\mathrm{Tu}$ (2018). The results are in line with the relevant literature (Al-Rahmi et al., 2019). Similar arguments could be extended to the concepts of compatibility, the complexity, observability and trialability. Compatibility influences continuous intention to use IoMT through motivation (regression estimate 0.743 ) and training (regression estimate 0.85 ) positively. Compatibility has a large correlation with motivation and training.

Complexity was found to influence continuous intention to use IoMT positively through training to use IoMT. Trialability and observability were not found to have any significant relationship with motivation to use IoMT. The complexity, e.g., lack of skilled staff to manage a multivendor environment (Haddud et al., 2017), can affect motivation of users. The results show further that training (regression estimate 0.244) influences continuous intention to use by overcoming complexities. When this result is combined with the compatibility, then it can be seen that higher compatibility motivates the healthcare professionals while higher complexity does not motivate the users (this explains the rejection of hypothesis H2a). The explanation for this may be that IoMT trials or observations about how to use IoMT in healthcare settings are seldom useful. This explains why the connections between trialability and motivation, as well as observability and motivation, were found to be statistically insignificant (this explains the rejection of $\mathrm{H} 4 \mathrm{a}$ and $\mathrm{H} 5 \mathrm{a}$ ). The above observations

Table 8 Moderation effect

\begin{tabular}{|c|c|c|c|c|}
\hline & Estimate & S.E. & C.R. & $\mathrm{P}$ \\
\hline MMOT1345 <--- MAWS1234 & 0.748 & 0.134 & 5.591 & $* * *$ \\
\hline MMOT1345 <--- MRA245 & 0.579 & 0.099 & 5.831 & $* * *$ \\
\hline MMOT1345 <--- MULTIAWSRA & -0.079 & 0.034 & -2.316 & 0.021 \\
\hline
\end{tabular}

Table 9 Coding of moderated and moderating variables

\begin{tabular}{ll}
\hline Code & Construct \\
\hline MAWS1234 & Mean AI Awareness \\
MRA245 & Mean Relative advantage \\
MCPX23 & Mean Complexity \\
MCMP1234 & Mean Compatibility \\
MMOT1345 & Mean Motivation \\
MTRN & Mean Training \\
MULTIAWSRA & Multiply: (MAWS1234* MRA245) \\
MULTIAWSCPX & Multiply: (MAWS1234* MCPX23) \\
MULTIAWSCMP & Multiply: (MAWS1234*MCMP1234) \\
\hline
\end{tabular}

are in line with the findings of others (Jalo et al., 2020; Vagnani \& Volpe, 2017).

Furthermore, the overall effect (Table 10) of relative advantage, complexity, and compatibility influence indirectly continuous intention to use IoMT positively (regression estimates $0.14,0.363$ and 0.037 respectively). The results could be interpreted in a way that compatibility is the most significant DOI factor that helps in the diffusion of IoMT followed by its relative advantage. Complexity appears to have no specific significance in enhancing continuous usage when considered as part of the total effect of independent variables.

Regarding the moderators, it can be seen that age was not found to be correlated with any of the constructs, namely motivation, training and continuous intention to use IoMT. Similar results are reported by others in the literature (Cabeza-Ramírez et al., 2020; Rajmohan \& Johar, 2020) confirming that the current research outcomes are in line with others' findings. Novelty seeking behaviour of healthcare professionals was also found to be not moderating the relationships between motivation, training and continuous intention to use IoMT. Similar findings have also been reported by other researchers (Andreasen \& Streukens, 2013; Hsiao \& Yang, 2010).

Finally, AI awareness as a moderator was found to positively influence the relationships, namely the relative advantage to motivation (regression estimate -0.079 ) and compatibility (regression estimate -0.178 ) to motivation negatively. That is to say, the higher the AI awareness, the influence of relative advantage and compatibility will be lower on the motivation. This result is a new finding. This signifies that if AI moderates the diffusion of IoMT, then the relevance of relative advantage and compatibility could diminish making the use of IoMT more automatic and less difficult to use on the part of the healthcare professionals, thus increasing the use of IoMT and motivating users to integrate IoMT in their practice (Abubakar \& Ahmad, 2013). 
Table 10 Regression results of moderation

\begin{tabular}{|c|c|c|c|c|c|c|c|}
\hline Moderated relationship & Moderator & Multiplication factor & Regression estimate & $\mathrm{R}^{2}$ & $\mathrm{p}$ value & Hypothesis & Accepted? \\
\hline $\mathrm{RA} \rightarrow \mathrm{MOT}$ & MAWS1234 & MULTIAWSRA & -0.079 & $55 \%$ & 0.021 & $\mathrm{H} 12$ & Accepted \\
\hline $\mathrm{CPX} \rightarrow \mathrm{MOT}$ & MAWS1234 & MULTIAWSCPX0 & .026 & - & 0.496 & H13 & Rejected \\
\hline $\mathrm{CMP} \rightarrow \mathrm{MOT}$ & MAWS1234 & MULTIAWSCMP & -0.178 & $60 \%$ & $* * *$ & H14 & Accepted \\
\hline $\mathrm{RA} \rightarrow \mathrm{TRN}$ & MAWS1234 & MULTIAWSRA & -0.037 & - & 0.287 & H15 & Rejected \\
\hline $\mathrm{CPX} \rightarrow \mathrm{TRN}$ & MAWS1234 & MULTIAWSCPX & -0.041 & - & 0.237 & H16 & Rejected \\
\hline $\mathrm{CMP} \rightarrow \mathrm{TRN}$ & MAWS1234 & MULTIAWSCMP & -0.056 & - & 0.159 & $\mathrm{H} 17$ & Rejected \\
\hline
\end{tabular}

\subsection{Theoretical Contributions}

Application of DOI to understand the diffusion of innovation is widely found in the literature for a single innovation at a single point of time (AlSheibani et al., 2020; Sayginer \& Ercan, 2020; Tran \& Cheng, 2017). However, when two interrelated innovations diffuse at the same time with the possibility of recurrent innovation underuse, whether DoI as a theory could be applied or not is clear in the literature. This implies that when a responsible AI as innovation is embedded in IoMT (another innovation), then how to explain the adoption rate or continuous use of IoMT is a major area not covered in the literature. Lin (2021) argues that DOI can address only single innovations diffusing and adopting at one time. However, there is evidence in the literature to show that researchers have combined more than one theory at a time to explain either adoption intentions (Stokey, 2020; Tran \& Cheng, 2017) or continuous intention to use (Huang et al., 2020).

However, research outcomes that explain the concurrent diffusion of two innovations and their influence on continuous intention to adopt in the presence of recurrent innovations (like earlier versions of IoMT or earlier versions of $\mathrm{AI}$ ) using DOI are not found in the extant literature. This research has provided insight into expanding Rogers' (2003) model to explain two interrelated innovations diffusing at the same time. Results of the research have shown that DOI factors relative advantage, complexity and compatibility determine continuous intention to use IoMT embedded with responsible AI through behavioural attributes motivation and training. At the same time responsible AI represented by AI awareness is seen to moderate the relationship between the determinant and the behavioural attributes. Thus, the IoMT is depicted as the determinant while responsible AI is depicted as the moderator. This implies that a new and novel extension of Rogers' (2003) DOI model was derived in this research that can explain the concurrent diffusion of two interrelated innovations. This is the case even when the recurrent use of the innovations could be taking place which is signified by the continuous intention to use the innovation. This theoretical extension was validated by showing the variance introduced in motivation, training and continuous intention to use IoMT by the determinants to the extent of $65 \%, 54 \%$ and $35 \%$ respectively. Similarly, the extent of moderation by AI awareness of the valid relationships between relative advantage and compatibility on the one hand and motivation on the other is shown to be $55 \%$ and $60 \%$ respectively. These measurements confirm the theoretical implications of this research.

\subsection{Practical Implications}

The research outcomes have important implications for the healthcare practitioners. The research provides a realistic and parsimonious method to predict the continuous intention to use IoMT that is constructed with responsible AI. Improving motivation to understand AI and training to use IoMT associated with AI responsibility when IoMT is still diffusing is a plausible and practical solution that can allow healthcare professionals to continuously use it.
Table 11 Total effect of independent variables on the dependent variable

\begin{tabular}{llllll}
\hline & Complexity & Compatibility & $\begin{array}{l}\text { Relative } \\
\text { advantage }\end{array}$ & Training & Motivation \\
\hline Training & 0.239 & 0.818 & 0.155 & 0.000 & 0.000 \\
Motivation & -0.055 & 0.736 & 0.248 & 0.000 & 0.000 \\
$\begin{array}{l}\text { Continuous intention to use } \\
\text { IoMT }\end{array}$ & 0.024 & 0.456 & 0.130 & 0.196 & 0.402 \\
\hline
\end{tabular}


The study shows that compelling relative advantage can motivate healthcare professionals to use IoMT and influence them to get trained to overcome the complexity of using it. The results point out that compatibility is an important driver of both motivation and training to use IoMT. While prior studies hypothesise that users are often intimidated by complex technologies and innovations such as AI and IoMT when it comes to their continuous use, our study negates this assumption. In a healthcare context, both observability and trialability were not related to motivation to use IoMT implying that users do not consider it a need to observe others using the technology or get an opportunity to try it out before using it. Furthermore, results showed that AI awareness is an important moderator of the relationship between the complexity and the motivation.

Since IoMT is a technology-based solution, it is usual that such technological solutions continuously change with innovations released frequently with upgraded technology making the continuous usage of IoMT a concern. However, the results of this research clearly show that diffusion factors such as relative advantage, compatibility, and complexity alongside the responsible AI influence behavioural traits motivation and training, can provide a predictable model that could be used to enhance continuous intention to use IoMT. In addition, the results show that novelty seeking behaviour and age do not affect the diffusion of AI based IoMT. These findings imply that despite risks, problems of ethics and challenges associated with AI, healthcare professionals could continuously use IoMT by improving their motivation and training to use IoMT.

\subsection{Limitations and Future Research Directions}

The main limitation of this research has been the use of isolated examples of moderators found in the literature and restricting the determinants to the ones defined by the theory of DOI. Had there been additional determinants there was a possibility that the results of this research could have been different. For instance, perceived enjoyment to use IoMT could be a determinant (Al-Rahmi et al., 2019). Approaching hospitals and healthcare professionals to collect data was challenging as those professionals were completely involved in fighting COVID-19. Challenges included summary rejection to participate in the survey to the risk of contracting COVID-19 by the researcher due to the proximity of some officials of hospitals when approached to gain access to the healthcare professionals. This reduced the number of participants to some extent. In non-COVID-19 environment, better participation of subjects and the research outcomes could have been different. Furthermore, the current research was conducted in one country and replicating the research in other countries could provide different outcomes (Kumar et al., 2018; Obeidat et al., 2020; Patil et al., 2018a; Rana et al., 2014, 2015; Williams et al., 2016). The future research can also apply the more advanced theory of adoption and diffusion of IoMT such as UTAUT (Dwivedi et al., 2019) and UTAUT2 (Tamilmani et al., 2021) and could come up with some more relevant constructs using the meta-analysis of such theories as well (Patil et al., 2018b).

\section{Conclusion}

The study examined the contradictions caused by AI being risky and complex technology that could easily dissuade healthcare professionals from using an AI based IoMT that promises improved healthcare to patients. From the results obtained in this research the following conclusions can be derived. Continuous intention to use IoMT is determined by DOI factors relative advantage, complexity, and compatibility, but indirectly through the mediators namely motivation and training to use IoMT. Continuous diffusion of AI based IoMT can lead to continuous intention to use IoMT by healthcare professionals. Awareness about AI provides knowledge about the problems including ethical and moral ones, that could be caused by AI. Motivation and training to use IoMT can enable the healthcare professionals to successfully handle the risks and complexities associated with AI leading to the responsible use of IoMT. Continuous intention to use IoMT occurs while the AI based IoMT is still diffusing. Continuous intention can also be predicted using relative advantage, complexity, and compatibility in the presence of two interventions and a moderator. Managers in healthcare settings now have a model to deal with problems caused by a risky and complex AI based IoMT. In those situations, it is possible to address the risks involved by motivating and training healthcare professionals in AI, thus avoiding complex situations that could lead to unethical decision making of healthcare professionals. Additionally, the model provides evidence on the necessity to exploit the relative advantage, compatibility and complexity of an AI based IoMT which in turn could motivate healthcare professionals to use AI based IoMT continuously. Finally, it can be concluded that the outcome of this research provides a rich knowledge on the utility and application of AI based IoMT but also under less severe circumstances. 


\section{Appendix A Definitions of constructs and items constituting them}

\begin{tabular}{|c|c|c|}
\hline Variable/Construct & Definition & Source \\
\hline Relative advantage & The degree to which an innovation is perceived as better than the idea it supersedes. & Rogers (1995) \\
\hline Compatibility & $\begin{array}{l}\text { The degree to which an innovation is perceived as being consistent with the existing values, past experiences, } \\
\text { and needs of potential adopters. }\end{array}$ & Rogers (1995) \\
\hline Complexity & The degree to which an innovation is perceived as being difficult to use & Rogers (1995) \\
\hline Observability & The degree to which the results of an innovation are visible to others & Rogers (1995) \\
\hline Trialability & $\begin{array}{l}\text { The degree to which an innovation may be experimented with on a limited basis before behavioural intention to } \\
\text { use IoMT }\end{array}$ & Rogers (1995) \\
\hline Novelty seeking & $\begin{array}{l}\text { Novelty seeking means to seek knowledge about new products or item which are created \& tested on adult } \\
\text { users or customers. Novelty seeking as a personality trait expressing excitement in reaction to new stimuli. }\end{array}$ & $\begin{array}{l}\text { Manning et al. } \\
\text { (1995) } \\
\text { Cloninger et al. } \\
\quad(1991)\end{array}$ \\
\hline Age & Age is major contributor to the understanding of the behavioural intention to use technology of people. & $\begin{array}{l}\text { Martins et al. } \\
\quad(2018)\end{array}$ \\
\hline AI awareness & Awareness is a form of knowledge that can be acquired actively or passively. & Rogers (2010) \\
\hline Motivation & Motivation has been defined as an emotion or desire operating on the will and causing it to act. & $\begin{array}{l}\text { Randall et al. } \\
\text { (2006) }\end{array}$ \\
\hline Training & $\begin{array}{l}\text { Training is the degree to which trainees effectively apply the knowledge, skills, and attitudes gained in a } \\
\text { training context to the job. }\end{array}$ & $\begin{array}{l}\text { Baldwin and Ford } \\
\text { (1988) }\end{array}$ \\
\hline
\end{tabular}

\section{Items for various constructs}

\begin{tabular}{|c|c|c|}
\hline Code & Item & Source \\
\hline CI1 & Given the chance, I intend to use IoMT applications & Venkatesh (2000); \\
\hline CI2 & I am willing to use IoMT applications in the near future & Venkatesh et al. (2012) \\
\hline $\mathrm{CI} 3$ & I will recommend IoMT applications to others & \\
\hline CI4 & I will continue using IoMT applications in the future & \\
\hline $\begin{array}{l}\text { RA1 } \\
\text { RA2 }\end{array}$ & $\begin{array}{l}\text { Using an IoMT application enables me to complete tasks faster. } \\
\text { Using an IoMT application improves the quality of work I do. }\end{array}$ & $\begin{array}{l}\text { Savoury (2019); Al-Rahmi et al. (2019); Moore } \\
\quad \text { and Benbasat (1991) }\end{array}$ \\
\hline RA3 & Using an IoMT application makes it easier to do my job. & \\
\hline RA4 & Using an IoMT enhances my effectiveness on the job. & \\
\hline RA5 & Using an IoMT gives me greater control over my work. & \\
\hline RA6 & Using an IoMT increases my productivity. & \\
\hline COMPLEX1 & The use of IoMT requires a lot of mental effort & Oliveira et al. (2014) \\
\hline $\begin{array}{l}\text { COMPLEX } \\
2\end{array}$ & The use of IoMT is frustrating & \\
\hline $\begin{array}{l}\text { COMPLEX } \\
3\end{array}$ & The use of IoMT is too complex for business operations & \\
\hline $\begin{array}{l}\text { COMPLEX } \\
4\end{array}$ & The skills needed to adopt IoT are too complex for employees of the firm & \\
\hline COMPAT1 & Using an IoMT is compatible with all aspects of my work. & Savoury (2019); Al-Rahmi et al. (2019); Moore \\
\hline COMPAT2 & Using an IoMT is completely compatible with my current situation. & and Benbasat (1991) \\
\hline COMPAT3 & I think that using an IoMT fits well with the way I like to work. & \\
\hline COMPAT4 & The use of IoMT is fully compatible with the value system of my workplace & \\
\hline $\begin{array}{l}\text { TRI1 } \\
\text { TRI2 }\end{array}$ & $\begin{array}{l}\text { I have had a great opportunity to try different IoT applications. } \\
\text { I am aware where I can go to try out many uses of IoT. }\end{array}$ & $\begin{array}{l}\text { Al-Rahmi et al. (2019); Moore and Benbasat } \\
\text { (1991) }\end{array}$ \\
\hline TRI3 & $\begin{array}{l}\text { Before deciding on whether to use IoT applications, I was in a position to properly try } \\
\text { them out. }\end{array}$ & \\
\hline TRI4 & $\begin{array}{l}\text { I was permitted to use IoT applications on a trial basis over a long and sufficient period } \\
\text { of time to see what it can do. }\end{array}$ & \\
\hline
\end{tabular}


(continued)

OBS1 I have seen what others do while using IoMT.

OBS2 In my organization, one sees IoMT applications used in different units.

OBS3 I have seen the use of IoMT outside my organisation

OBS4 I have had many opportunities to see IoMT being used

TRAIN1 My performance was satisfactory on the IoMT application training

TRAIN2 I was able to achieve the objectives of IoMT application training

TRAIN3 I could learn as much as possible from the training on IoMT

TRAIN4 I was able to benefit from the training on IoMT

TRAIN5 The training on IoMT significantly added to my knowledge

AWS1 I receive enough information about AI in from service provider of IoMT.

AWS2 I receive enough information about the benefits of AI integrated in IoMT.

AWS3 I receive enough information of using AI integrated in IoMT.

AWS4 I am aware of the education/training programs about using AI integrated in IoMT offered by the service provider

AWS5 I have come across campaigns by the service provider about using AI integrated in IoMT

NS1 While using IoMT, I am always seeking new ideas about IoMT

NS2 While using IoMT, I am always seeking new experience about IoMT

NS3 I do not prefer an unpredictable way while using IoMT but prefer the one without any change in my routine use of IoMT.

NS4 I like to continually change my way of dealing with IoMT activities.

NS5 I do not like meeting healthcare service providers who have new ideas about IoMT.

NS6 I like to experience novelty in IoMT

MOT2 I think it is interesting

MOT1 My job requires me to do it

MOT3 I feel good when using it

MOT4 I think that this activity is good for me

MOT5 I believe that this activity is important for me

Al-Rahmi et al. (2019); Moore and Benbasat

(1991)

Alias et al. (2019); Saks and Haccoun (2007); Noe (2010)

Al-Somali et al. (2009)

Mehrabian and Russell (1974); Dabholkar and Bagozzi (2002)

Guay et al. (2000); Vallerand et al. (1989)

\section{References}

Abildgaard, J., Saksvik, P., \& Nielsen, K. (2016). How to measure the intervention process? An assessment of qualitative and quantitative approaches to data collection in the process evaluation of organizational interventions. Frontiers in Psychology, 7, 1-10. https://doi. org/10.3389/fpsyg. 2016.01380

Abubakar, F. M., \& Ahmad, H. B. (2013). The moderating effect of technology awareness on the relationship between UTAUT constructs and behavioural intention to use technology: A conceptual paper. Australian journal of business and management research, 3(2), 14-23. www.ajbmr.com_articlepdf_aus-29-75i02n3a2.pdf (d1wqtxts1xzle7.cloudfront.net.

Agarwal, R., \& Prasad, J. (1999). Are individual differences germane to the acceptance of new information technologies? Decision Sciences, 30(2), 361-391. https://doi.org/10.1111/j.1540-5915.1999.tb01614. $\mathrm{x}$

Alam, M. Z., Hu, W., \& Barua, Z. (2018). Using the UTAUT model to determine factors affecting acceptance and use of mobile health (mHealth) services in Bangladesh. Journal of Studies in Social Sciences, 17(2), 137-172 https://core.ac.uk/download/pdf/ 229606775.pdf

Al-Gahtani, S. S. (2016). Empirical investigation of e-learning acceptance and assimilation: A structural equation model. Applied Computing and Informatics, 12(1), 27-50. https://doi.org/10.1016/j.aci.2014. 09.001

AL-Hadban, W. K. M., Yusof, S. A. M., \& Hashim, K. F. (2017). The barriers and facilitators to the adoption of new technologies in public healthcare sector: A qualitative investigation. International Journal of Business and Management, 12(1), 159-168. https://doi.org/10. 5539/ijbm.v12n1p159
Alias, S. A., Ong, M. H. A., Rahim, A. R. A., \& Hassan, R. (2019). The role of training design factors in influencing training effectiveness among public service employees. International Journal of Academic Research in Business and Social Sciences, 9(5), 898913. https://doi.org/10.6007/IJARBSS/v9-i5/6016

Al-Rahmi, W. M., Yahaya, N., Aldraiweesh, A. A., Alamri, M. M., Aljarboa, N. A., Alturki, U., \& Aljeraiwi, A. A. (2019). Integrating technology acceptance model with innovation diffusion theory: An empirical investigation on students' intention to use Elearning systems. IEEE Access, 7, 26797-26809. https://doi.org/10. 1109/ACCESS.2019.2899368

AlSheibani, S., Messom, C., \& Cheung, Y. (2020). Re-thinking the competitive landscape of artificial intelligence. In Proceedings of the 53rd Hawaii international conference on system sciences. Retrieved May 15, 2021 from https://scholarspace.manoa.hawaii. edu/bitstream/10125/64460/0579.pdf.

Al-Somali, S. A., Gholami, R., \& Clegg, B. (2009). An investigation into the acceptance of online banking in Saudi Arabia. Technovation, 29(2), 130-141. https://doi.org/10.1016/j.technovation.2008.07.004

Baldwin, T. T., \& Ford, J. K. (1988). Transfer of training: A review and directions for future research. Personnel Psychology, 41(1), 63-105. https://doi.org/10.1111/j.1744-6570.1988.tb00632.x

Bastari, A., Eliyana, A., Syabarrudin, A., Arief, Z., \& Emur, A. P. (2020). Digitalization in banking sector: The role of intrinsic motivation. Heliyon, 6(12), e05801.

Baudier, P., Ammi, C., \& Lecouteux, A. (2019). Employees' acceptance of the healthcare internet of things: A source of innovation in corporate human resource policies. Journal of Innovation Economics Management, 30(3), 89-111. https://doi.org/10.3917/jie.pr1.051

Bhatti, M. A., Battour, M. M., Sundram, V. P. K., \& Othman, A. A. (2013). Transfer of training: Does it truly happen? European 
Journal of Training and Development, 37(3), 273-297. https://oi. org/10.1108/03090591311312741

Buabeng-Andoh, C., Yaokumah, W., \& Tarhini, A. (2019). Investigating students' intentions to use ICT: A comparison of theoretical models. Education and Information Technologies, 24(1), 643-660. https:// doi.org/10.1007/s10639-018-9796-1

Cabeza-Ramírez, L. J., Sánchez-Cañizares, S. M., \& Fuentes-García, F. J. (2020). Motivations for the use of video game streaming platforms: The moderating effect of sex, age and self-perception of level as a player. International journal of environmental research and public health, 17(19), 7019. https://doi.org/10.3390/ijerph17197019

Chau, P. Y., \& Hui, K. L. (1998). Identifying early adopters of new IT products: A case of windows 95. Information \& Management, 33(5), 225-230. https://doi.org/10.1016/S0378-7206(98)00031-7

Chen, H., Li, L., \& Chen, Y. (2020). Explore success factors that impact artificial intelligence adoption on telecom industry in China. Journal of Management Analytics, 8(1), 36-68. https://doi.org/10.1080/ 23270012.2020 .1852895

Chiyangwa, T. B., \& (Trish) Alexander, P. (2016). Rapidly co-evolving technology adoption and diffusion models. Telematics and Informatics, 33(1), 56-76. https://doi.org/10.1016/j.tele.2015.05. 004

Choi, D., Chung, C. Y., Seyha, T., \& Young, J. (2020). Factors affecting organizations' resistance to the adoption of Blockchain Technology in Supply Networks. Sustainability, 12(21), 8882. https://doi.org/10. 3390/su12218882

Cloninger, C. R., Przybeck, T. R., \& Svrakic, D. M. (1991). The tridimensional personality questionnaire: U.S. normative data. Psychological Reports, 69(7), 1047-1057. https://doi.org/10.2466/ pr0.69.7.1047-1057

Coventry, L., \& Branley, D. (2018). Cybersecurity in healthcare: A narrative review of trends, threats and ways forward. Maturitas, 113, 48-52. https://doi.org/10.1016/j.maturitas.2018.04.008

Cronbach, L. J. (1946). Response sets and test validity. Educational and Psychological Measurement, 6(4), 475-494. https://doi.org/10. 1177/001316444600600405

Dabholkar, P. A., \& Bagozzi, R. P. (2002). An attitudinal model of technology-based self-service: Moderating effects of consumer traits and situational factors. Journal of the Academy of Marketing Science, 30(3), 184-201. https://doi.org/10.1177/ 0092070302303001

de Oca Munguia, O. M., Pannell, D. J., Llewellyn, R., \& StahlmannBrown, P. (2021). Adoption pathway analysis: Representing the dynamics and diversity of adoption for agricultural practices. Agricultural Systems, 191, 103173.

Deng, Z., Hong, Z., Ren, C., Zhang, W., \& Xiang, F. (2018). What predicts patients' adoption intention toward mHealth services in China: Empirical study. JMIR mHealth and uHealth, 6(8), e172 https://preprints.jmir.org/preprint/9316

Dignum, V. (2017). Responsible artificial intelligence: Designing AI for human values. ITU Journal, ICT Discoveries, 1, 1-8.

Dwivedi, Y. K., Rana, N. P., Jeyaraj, A., Clement, M., \& Williams, M. D. (2019). Re-examining the unified theory of acceptance and use of technology (UTAUT): Towards a revised theoretical model. Information Systems Frontiers, 21(3), 719-734.

Ericsson. (2015). Annual Report, 2015 Retrieved January 7, 2021, from http://mb.cision.com/Main/15448/2245135/661197.pdf

Franke, N., Von Hippel, E., \& Schreier, M. (2006). Finding commercially attractive user innovations: A test of lead-user theory*. Journal of Product Innovation Management, 23(4), 301-315. https://doi.org/ 10.1111/j.1540-5885.2006.00203.x

Fry, A., Ryley, T., \& Thring, R. (2018). The influence of knowledge and persuasion on the decision to adopt or reject alternative fuel vehicles. Sustainability, 10(9), 2997. https://doi.org/10.3390/su10092997
Gaynor, M., Ho, K., \& Town, R. J. (2015). The industrial organization of health-care markets. Journal of Economic Literature, 53(2), 235 284. https://doi.org/10.1257/jel.53.2.235

Ghubaish, A., Salman, T., Zolanvari, M., Unal, D., Al-Ali, A., \& Jain, R. (2021). Recent advances in the internet-of-medical-things (IoMT) systems security. IEEE Internet of Things Journal, 8(11), 87078718. https://doi.org/10.1109/jiot.2020.3045653

Giri, A., Chatterjee, S., Paul, P., Chakraborty, S., \& Biswas, S. (2019). Impact of smart applications of IoMT (internet of medical things) on health-care domain in India. International journal of recent technology and engineering, 8(4), 881-885. https://doi.org/10.35940/ijrte. d7474.118419

Gómez-González, E., Gomez, E., Márquez-Rivas, J., Guerrero-Claro, M., Fernández-Lizaranzu, I., Relimpio-López, M.I., Dorado, M.E., Mayorga-Buiza, M.J., Izquierdo-Ayuso, G. and Capitán-Morales, L. (2020). Artificial intelligence in medicine and healthcare: A review and classification of current and near-future applications and their ethical and social impact. arXiv preprint arXiv:2001.09778.

Guay, F., Vallerand, R. J., \& Blanchard, C. (2000). On the assessment of situational intrinsic and extrinsic motivation: The situational motivation scale (SIMS). Motivation and Emotion, 24(3), 175-213. https://doi.org/10.1023/A:1005614228250

Gul, M. S., \& NezamiFar, E. (2020). Investigating the interrelationships among occupant attitude, knowledge and behaviour in LEEDcertified buildings using structural equation modelling. Energies, 13(12), 3158. https://doi.org/10.3390/en13123158

Haddud, A., DeSouza, A., Khare, A., \& Lee, H. (2017). Examining potential benefits and challenges associated with the internet of things integration in supply chains. Journal of Manufacturing Technology Management, 28(8), 1055-1085. https://doi.org/10. 1108/jmtm-05-2017-0094

Hair, J. F., Black, W. C., Babin, B. J., Anderson, R. E., \& Tatham, R. L. (2006). Multivariate data analysis (6th ed.). Pearson University Press.

Haji. J. (2018). Cyber security: know your Blindspots, bizbahrain,[online]. Retrieved December 28, 2020 from http:// bizbahrain.com/magazine/BizBahrain-Nov-Dec-2018.pdf

Hardgrave, B. C., Davis, F. D., \& Riemenschneider, C. K. (2003). Investigating determinants of software developers' intentions to follow methodologies. Journal of Management Information Systems, 20(1), 123-151. https://doi.org/10.1080/07421222.2003.11045751

Holmes-Smith, P., Coote, L., \& Cunningham, E. (2006). Structural equation modeling: From the fundamentals to advanced topics. In School Research. Evaluation and Measurement Services.

Hooper, D., Coughlan, J., \& Mullen, M. R. (2008). Structural equation modelling: guidelines for determining model fit. Electronic Journal of Business Research Methods, 6(1), 53-60.

Hsiao, C., \& Yang, C. (2010). Predicting the travel intention to take high speed rail among college students. Transportation Research Part F: Traffic Psychology and Behaviour, 13(4), 277-287. https://doi.org/ 10.1016/j.trf.2010.04.011

Huang, C., Wang, H., Yang, C., \& Shiau, S. J. (2020). A derivation of factors influencing the diffusion and adoption of an open source learning platform. Sustainability, 12(18), 7532. https://doi.org/10. $3390 /$ su12187532

Huang, M. H., \& Rust, R. T. (2018). Artificial intelligence in service. Journal of Service Research, 21(2), 155-172. https://doi.org/10. $1177 / 1094670517752459$

Jacob, C., Sanchez-Vazquez, A., \& Ivory, C. (2020). Social, organizational, and technological factors impacting clinicians' adoption of mobile health tools: systematic literature review. JMIR mHealth and uHealth, 8(2), e15935. https://doi.org/10.2196/preprints.15935

Jaleel, A., Mahmood, T., Hassan, M. A., Bano, G., \& Khurshid, S. K. (2020). Towards medical data interoperability through collaboration of healthcare devices. IEEE Access, 8, 132302-132319. https://doi. org/10.1109/ACCESS.2020.3009783 
Jalo, H., Pirkkalainen, H., Torro, O., Lounakoski, M., \& Puhto, J. (2020). Enabling factors of social virtual reality diffusion in organizations, In Proceedings of the 28th European Conference on Information Systems (ECIS): An Online AIS Conference (pp. 1-15). in Proceedings of the 28th European Conference on Information Systems (ECIS). https://tutcris.tut.fi/portal/files/21890399/ ENABLING_FACTORS_OF_SOCIAL_VIRTUAL_REALITY DIFFUSION_IN_ORGAN̄IZAT.pdf.

Kamilaris, A., \& Botteghi, N. (2020). The penetration of internet of things in robotics: Towards a web of robotic things. Journal of Ambient Intelligence and Smart Environments, 12(6), 491-512. https://doi. org/10.3233/ais-200582

Karakaya-Ozyer, K., \& Aksu-Dunya, B. (2018). A review of structural equation modeling applications in Turkish educational science literature, (2010-2015). International Journal of Research in Education and Science, 4(1), 279-291. https://doi.org/10.21890/ijres.383177

Kim, S., Bae, J., \& Jeon, H. (2019). Continuous intention on accommodation apps: Integrated value-based adoption and expectationconfirmation model analysis. Sustainability, 11(6), 1578. https:// doi.org/10.3390/su11061578

Kumar, A., Mangla, S. K., Luthra, S., Rana, N. P., \& Dwivedi, Y. K. (2018). Predicting changing pattern: Building model for consumer decision making in digital market. Journal of Enterprise Information Management, 31(5), 674-703.

Leal, E. A., \& Albertin, A. L. (2015). Construindo Uma escala multiitens para avaliar os fatores determinantes do uso de inovação tecnologica na educação a distância. Review of Administration and Innovation, 12(2), 317-343. https://doi.org/10.11606/rai.v12i2.100344

Lee, D., \& Yoon, S. N. (2021). Application of artificial intelligence-based Technologies in the Healthcare Industry: Opportunities and challenges. International Journal of Environmental Research and Public Health, 18(1), 271. https://doi.org/10.3390/ijerph18010271

Lee, M. K., Cheung, C. M., \& Chen, Z. (2005). Acceptance of internetbased learning medium: The role of extrinsic and intrinsic motivation. Information \& Management, 42(8), 1095-1104. https://doi. org/10.1016/j.im.2003.10.007

Li, D., Hu, Y., Pfaff, H., Wang, L., Deng, L., Lu, C., Xia, S., Cheng, S., Zhu, X., \& Wu, X. (2020). Determinants of patients' intention to use the online inquiry services provided by internet hospitals: Empirical evidence from China. Journal of Medical Internet Research, 22(10), e22716 https://preprints.jmir.org/preprint/22716

Lin, F. (2021). Understanding diffusion of recurrent innovations. arXiv preprint arXiv:2101.05094.

Lu, Y., Papagiannidis, S., \& Alamanos, E. (2018). Internet of things: A systematic review of the business literature from the user and organisational perspectives. Technological Forecasting and Social Change, 136, 285-297. https://doi.org/10.1016/j.techfore.2018.01. 022

Manning, M., Manning, G., Long, R., \& Kamii, C. (1995). Development of kindergartners' ideas about what is written in a written sentence. Journal of Research in Childhood Education, 10(1), 29-36. https:// doi.org/10.1080/02568549509594685

Mansour, N., Rafeh, W., \& Afram, G. (2019). The role of self-awareness augmented artificial intelligence and enhanced leadership competencies in developing future academic physicians. World Family Medicine Journal/Middle East Journal of Family Medicine, 17(10), 27-35. https://doi.org/10.5742/mewfm.2019.93687

Martins, B., Florjanczyk, J., Jackson, N. J., Gatz, M., \& Mather, M. (2018). Age differences in emotion regulation effort: Pupil response distinguishes reappraisal and distraction for older but not younger adults. Psychology and Aging, 33(2), 338-349. https://doi.org/10. 1037/pag0000227

Marzouki, R., \& Belkahla, W. (2019). The impact of lead users on innovation success. Innovation \& Management Review, 17(1), 86-111. https://doi.org/10.1108/inmr-12-2018-0093
Matheny, M., Israni, S. T., Ahmed, M., \& Whicher, D. (2019). Artificial intelligence in health care: The hope, the hype, the promise, the peril. NAM special publication. Washington, DC: National Academy of medicine, 154. Retrieved March 11, 2021 from https://nam.edu/wpcontent/uploads/2019/12/AI-in-Health-Care-PREPUB-FINAL.pdf.

Mavrogiorgou, A., Kiourtis, A., Touloupou, M., Kapassa, E., \& Kyriazis, D. (2019). Internet of medical things (IoMT): Acquiring and transforming data into HL7 FHIR through 5G network slicing. Emerg. Sci. J, 3(2), 64-77.

McRae, L., Ellis, K., \& Kent, M. (2018). Internet of things (IoT): Education and technology. The relationship between education and technology for students with disabilities. Retrieved February 5, 2021 from https://www.voced.edu.au/content/ngv\%3A79260.

Mehrabian, A., \& Russell, J. A. (1974). An approach to environmental psychology (pp. 216-217). The Massachusetts Institute of Technology.

Miao, S., Rhee, J., \& Jun, I. (2020). How much does extrinsic motivation or intrinsic motivation affect job engagement or turnover intention? A comparison study in China. Sustainability, 12(9), 3630. https:// doi.org/10.3390/su12093630

Miraz, M., Ali, M., Excell, P., \& Picking, R. (2018). Internet of nanothings, things and everything: Future growth trends. Future Internet, 10(8), 68. https://doi.org/10.3390/fi10080068

Mohammadi, M. M., Poursaberi, R., \& Salahshoor, M. R. (2018). Evaluating the adoption of evidence-based practice using Rogers's diffusion of innovation theory: A model testing study. Health promotion perspectives, $8(1)$, 25-32. https://doi.org/10.15171/hpp. 2018.03

Moore, G. C., \& Benbasat, I. (1991). Development of an instrument to measure the perceptions of adopting an information technology innovation. Information Systems Research, 2(3), 192-222. https://doi. org/10.1287/isre.2.3.192

NHRA. (2019). Annual Report 2016. Retrieved January 11, 2021 from https://www.nhra.bh/About/AnnualReport/MediaHandler/ ImageHandler/documents/About/Annual\%20Report/NHRA\% 20Annual\%20Report\%202019.pdf.

Nijeweme-d'Hollosy, W. O., Van Velsen, L., Huygens, M., \& Hermens, H. (2015). Requirements for and barriers towards interoperable eHealth technology in primary care. IEEE Internet Computing, 19(4), 10-19. https://doi.org/10.1109/mic.2015.53

Obeidat, Z., Algharabat, R. S., Alalwan, A., Xiao, S. H., Dwivedi, Y. K., \& Rana, N. P. (2020). Narcissism, interactivity, community, and online revenge behavior: The moderating role of social presence among Jordanian consumers. Computers in Human Behavior, 104, 106170.

Noe, R. A. (2010). Employee training and development (5th ed.). Mc Graw Hill.

Oliveira, T., Thomas, M., \& Espadanal, M. (2014). Assessing the determinants of cloud computing adoption: An analysis of the manufacturing and services sectors. Information and Management, 51(5), 497-510. https://doi.org/10.1016/j.im.2014.03.006

Ozkeser, B. (2019). Impact of training on employee motivation in human resources management. Procedia Computer Science, 158, 802-810. https://doi.org/10.1016/j.procs.2019.09.117

Padyab, A., Habibipour, A., Rizk, A., \& Ståhlbröst, A. (2019). Adoption barriers of IoT in large scale pilots. Information, 11(1), 23. https:// doi.org/10.3390/info11010023

Pang, S., Bao, P., Hao, W., Kim, J., \& Gu, W. (2020). Knowledge sharing platforms: An empirical study of the factors affecting continued use intention. Sustainability, 12(6), 2341. https://doi.org/10.3390/ su12062341

Park, H., \& Choi, S. O. (2019). Digital innovation adoption and its economic impact focused on path analysis at national level. Journal of open innovation: Technology, market, and complexity, 5(3), 56. https://doi.org/10.3390/joitmc5030056 
Patil, P. P., Rana, N. P., \& Dwivedi, Y. K. (2018a). Digital payments adoption research: A review of factors influencing consumer's attitude, intention and usage. In conference on e-business, e-services and e-society (pp. 45-52). Springer.

Patil, P. P., Rana, N. P., \& Dwivedi, Y. K. (2018b). Digital payments adoption research: A meta-analysis for generalising the effects of attitude, cost, innovativeness, mobility and price value on behavioural intention. In International working conference on transfer and diffusion of IT (pp. 194-206). Springer.

Rajmohan, R., \& Johar, M. G. M. (2020). Influence of social moderators on the Internet of things of Srilankan healthcare services. International Journal of Recent Technology and Engineering, 9(1), 2154-2164. https://doi.org/10.35940/ijrte.a2815.059120

Rana, N., Dwivedi, Y., Weerakkody, V., \& Piercy, N. (2014). Examining adoption of electronic district (e-district) system in Indian context: A validation of extended technology acceptance model. AMCIS.

Rana, N. P., Dwivedi, Y. K., \& Lal, B. (2015). Factors influencing Citizen's adoption of an E-government system: Validation of the decomposed theory of planned behavior. UKAIS, University of Oxford.

Randall, J., Novotny, S., \& Larson, S. (2006). Is it Really all about the Money? Motivating Employees in the 21st Century. Journal of Undergraduate Research at Minnesota State University, Mankato, 6(1), $18 \mathrm{https://cornerstone.lib.mnsu.edu/cgi/viewcontent.cgi?}$ article $=1125 \&$ context $=$ jur

Reardon, S. (2019). Rise of robot radiologists. Nature, 576(7787), S54 S58. https://doi.org/10.1038/d41586-019-03847-z

Robinson, W. P., Cambon-Thomsen, A., Borot, N., Klitz, W., \& Thomson, G. (1991). Selection, hitchhiking and disequilibrium analysis at three linked loci with application to. HLA data Genetics, 129(3), 931-948. https://doi.org/10.1093/genetics/129.3. 931

Rodrigues, J. J., Segundo, D. B. D. R., Junqueira, H. A., Sabino, M. H., Prince, R. M., Al-Muhtadi, J., \& De Albuquerque, V. H. C. (2018). Enabling technologies for the internet of health things. Ieee Access, 6, 13129-13141. https://doi.org/10.1109/ACCESS.2017.2789329

Rogers, E. M. (2010). Diffusion of innovations: Simon and Schuster.

Rogers, E. M. (1995). Diffusion of innovations (4th ed.). Free Press. Rogers, E. M. (2003). Diffusion of innovations (5th ed.). Free Press.

Ryu, H. S. (2018). Understanding benefit and risk framework of fintech adoption: Comparison of early adopters and late adopters. Proceedings of the 51st Hawaii International Conference on System Sciences. https://doi.org/10.24251/HICSS.2018.486

Saarikko, T., Westergren, U. H., \& Blomquist, T. (2017). The internet of things: Are you ready for what's coming? Business Horizons, 60(5), 667-676. https://doi.org/10.1016/j.bushor.2017.05.010

Safavi, K., \& Kalis, B. (2019). How AI can change the future of health care. Harvard Business Review Retrieved March 05, 2021 from https://hbr.org/webinar/2019/02/how-ai-can-change-the-future-ofhealth-care.

Saks, A., \& Haccoun, R. (2007). Managing performance through training and development (4th ed.). Nelson and Thompson Ltd..

Sayginer, C., \& Ercan, T. (2020). Benefits and challenges of cloud computing in production and service sector in Izmir, the city of Turkey. Humanities \& Social Sciences Reviews, 8(3), 434-446. https://doi. org/10.18510/hssr.2020.8347

Savoury, R. D. (2019). Influential determinants of internet of things adoption in the US manufacturing sector. Retrieved august 05, 2020 from https://scholarworks.waldenu.edu/cgi/viewcontent.cgi? Article= 8355\&context=dissertations

Schermelleh-Engel, K., Moosbrugger, H., \& Müller, H. (2003). Evaluating the fit of structural equation models: Tests of significance and descriptive goodness-of-fit measures. Methods of Psychological Research Online, 8(2), 23-74.

Schreiber, J. B., Nora, A., Stage, F. K., Barlow, E. A., \& King, J. (2006). Reporting structural equation modeling and confirmatory factor analysis results: A review. The Journal of Educational Research, 99(6), 323-338. https://doi.org/10.3200/JOER.99.6.323-338

Scott, P., \& Yampolskiy, R. (2019). Classification schemas for artificial intelligence failures. Delphi - Interdisciplinary Review of Emerging Technologies, 2(4), 186-199. https://doi.org/10.21552/delphi/2019/ $4 / 8$

Sekaran, U., \& Bougie, R. (2016). Research methods for business: A skill building approach (7th ed.). John Wiley \& Sons.

Shah, R., \& Chircu, A. (2018). IoT and AI in healthcare: A systematic literature review. Issues In Information Systems, 19(3), 33-41. https://doi.org/10.48009/3_iis_2018_33-41

Shahbaz, M., Gao, C., Zhai, L., Shahzad, F., \& Hu, Y. (2019). Investigating the adoption of big data analytics in healthcare: The moderating role of resistance to change. Journal of Big Data, 6(1). https://doi.org/10.1186/s40537-019-0170-y

Stokey, N. L. (2020), Technology diffusion. NBER working paper no. w27466. Retrieved July, 2020, from https://bfi.uchicago.edu/wpcontent/uploads/BFI WP 202094.pdf].

Sugandini, D., Feriyanto, N., Muafi, M., Hadioetomo, H., \& Hapsoro Darpito, S. (2018). The influence of novelty seeking behavior and autonomy toward new product trial in the context of e-business learning: The role of mediation of perceived behavioral control. Journal of Entrepreneurship Education, 21(3), 1-9.

Taherdoost, H. (2018). A review of technology acceptance and adoption models and theories. Procedia Manufacturing, 22, 960-967. https:// doi.org/10.1016/j.promfg.2018.03.137

Tamilmani, K., Rana, N. P., Wamba, S. F., \& Dwivedi, R. (2021). The extended unified theory of acceptance and use of technology (UTAUT2): A systematic literature review and theory evaluation. International Journal of Information Management, 57, 102269.

Taylor K., Sanghera A., Steedman M., Thaxter M.. (2018). Medtech and the internet of medical things: How connected medical devices are transforming health care. Deloitte. Retrieved November 17, 2020 from https://www2.deloitte.com/content/dam/Deloitte/global/ Documents/Life-SciencesHealth-Care/gx-lshc-medtech-iomtbrochure.pdf:

Tran, T. C. T., \& Cheng, M. S. (2017). Adding innovation diffusion theory to technology acceptance model: Understanding Consumers' intention to use biofuels in Viet Nam. International review of management and business research, 6(2), $595 \mathrm{https}: / /$ www.irmbrjournal.com/papers/1495453550.pdf

Tristani, L., Tomasone, J., Fraser-Thomas, J., \& Bassett-Gunter, R. (2020). Examining Factors Related to Teachers' Decisions to Adopt Teacher-Training Resources for Inclusive Physical Education. Canadian Journal of Education, 43(2), 367-396.

Tsao, W. C., \& Yang, F. J. (2017). Factors that influence the intention to use Mobile shopping platforms which feature virtual shelves and QR codes based on TAM. International Review of Management and Business Research, 2(6), 758-776 https://www.irmbrjournal. com/papers/1498027678.pdf

Tu, M. (2018). An exploratory study of internet of things (IoT) adoption intention in logistics and supply chain management. The International Journal of Logistics Management, 29(1), 131-151. https://doi.org/10.1108/ijlm-11-2016-0274

Um, T., Kim, T., \& Chung, N. (2020). How does an intelligence chatbot affect customers compared with self-service technology for sustainable services? Sustainability, 12(12), 5119. https://doi.org/10.3390/ su12125119

Vagnani, G., \& Volpe, L. (2017). Innovation attributes and managers' decisions about the adoption of innovations in organizations: A meta-analytical review. International Journal of Innovation Studies, 1(2), 107-133. https://doi.org/10.1016/j.ijis.2017.10.001

Vallerand, R. J., Blais, M. R., Briere, N. M., \& Pelletier, L. G. (1989). The construction and validation of a new measure of motivation toward education, Ecmelle-De-motivation-En-education (Eme). Canadian Journal of Behavioural Science-Revue Canadienne Des Sciences 
Du Comportement, 21(3), 323-349. https://doi.org/10.1037/ h0079855

Van der Heijden. (2004). User acceptance of hedonic information systems. MIS Quarterly, 28(4), 695-704. https://doi.org/10.2307/ 25148660

Venkatesh, V. (2000). Determinants of perceived ease of use: Integrating control, intrinsic motivation, and emotion into the technology acceptance model. Information Systems Research, 11(4), 342-365. https://doi.org/10.1287/isre.11.4.342.11872

Venkatesh, V., Speier, C., \& Morris, M. G. (2002). User acceptance enablers in individual decision making about technology: Toward an integrated model. Decision Sciences, 33(2), 297-316. https://doi. org/10.1111/j.1540-5915.2002.tb01646.x

Venkatesh, V., Thong, J. Y., \& Xu, X. (2012). Consumer acceptance and use of information technology: Extending the unified theory of acceptance and use of technology. MIS Quarterly, 36(1), 157-178. https://doi.org/10.2307/41410412

Williams, M., Rana, N., Roderick, S., \& Clement, M. (2016). Gender, age, and frequency of internet use as moderators of citizens' adoption of electronic government. Americas conference on information systems.

Winchcomb, T., Massey, S., \& Beastall, P. (2017). Review of latest developments in the Internet of Things, Cambridge Consultants Ltd, Ofcom contract number 1636 (MC370). https://www.ofcom. org.uk/_data/assets/pdf_file/0007/102004/Review-of-latestdevelopments-in-the-Internet-of-Things.pdf.

Zeadally, S., Siddiqui, F., Baig, Z., \& Ibrahim, A. (2019). Smart healthcare. PSU Research Review, 4(2), 149-168. https://doi.org/ 10.1108/prr-08-2019-0027

Zhanyou, W., Dongmei, H., \& Yaopei, Z. (2020). How to improve users' intentions to continued usage of shared bicycles: A mixed method approach. PLoS One, 15(2), e0229458. https://doi.org/10.1371/ journal.pone. 0229458

Publisher's Note Springer Nature remains neutral with regard to jurisdictional claims in published maps and institutional affiliations.

Fatema Al-Dhaen is currently a $\mathrm{PhD}$ candidate at the School of Management at the University of Bradford, UK. Her research interests include Internet of Things (IoT), Internet of Medical things (IoMT), Artificial intelligence (AI), Mobile Health, Mobile programming, healthcare, Assistive technology, Media and telecommunication. She has a master's degree with distinction in information technology in mathematical sciences. She has been teaching Information technology and web development in many universities in Bahrain.
Jiachen Hou is Assistant Professor of Operations and Information Management in the School of Management at the University of Bradford. Her current research mainly focuses on IoT-enabled process improvement in the healthcare industry, the impact of Industry 4.0 on Servitization and Circular Economy in manufacturing industries, and multi-criteria decision analysis. Jiachen has been engaged in a range of professional activities. She has reviewed articles for journals such as Supply Chain Management-An International Journal, European Management Journal, International Journal of Design Engineering, Journal of Strategic Contracting and Negotiation, Public Money and Management, etc.

Nripendra P. Rana * is a Professor in Marketing at the College of Business and Economics at Qatar University, Doha, Qatar. His current research interests focus primarily on adoption and diffusion of emerging ICTs, e-commerce, m-commerce, e-government and digital and social media marketing. He has published more than 200 papers in a range of leading academic journals, conference proceedings, books etc. He has coedited five books on digital and social media marketing, emerging markets and supply and operations management. He has also co-edited special issues, organised tracks, mini-tracks and panels in leading conferences. He is a Chief Editor of International Journal of Electronic Government Research and an Associate Editor of International Journal of Information Management. He is a Senior Fellow of the Higher Education Academy (SFHEA) in the UK. He is also a Distinguished Visiting Professor at University of Johannesburg, South Africa.

Vishanth Weerakkody is a Professor of Digital Governance in the School of Management at University of Bradford. His current research and teaching are multidisciplinary and centred around public sector policy implementation, process transformation through digital technologies, social innovation and the implementation, diffusion, and adoption of disruptive technologies in society. His passion for solving societal problems through research and innovation has allowed him to attract over $£ 25$ millions of R\&D funding over the last few years from the EU, ESRC, Qatar Foundation, British Council and UK Local Government. Given the changing landscape of UK within Europe, he is particularly passionate about research and innovation to tackle ongoing societal challenges, including the use of emerging technologies to transform health and social care and using community led innovation to deal with increasing levels of scarcity and poverty. Prior to joining academia, he worked in several multinational organisations including BAT Industries and IBM. 